\title{
A comparison of stage-specific all-cause mortality between testicular sex cord stromal tumors and germ cell tumors: results from the National Cancer Database
}

Kyle B. Zuniga ${ }^{1,2,3^{*}}$, Samuel L. Washington $\mathrm{II}^{1}$, Sima P. Porten ${ }^{1}$ and Maxwell V. Meng ${ }^{1}$

\begin{abstract}
Background: Testicular sex cord stromal tumors (SCSTs) are managed similarly to germ cell tumors (GCTs); however, few studies have directly compared outcomes between these tumor types. Using the National Cancer Database (NCDB), we sought to compare overall and stage-specific all-cause mortality (ACM) between SCSTs versus GCTs.

Methods: NCDB was queried for patients diagnosed with SCSTs and GCTs between 2004 and 2013. Descriptive statistics were used to compare sociodemographic and clinical characteristics between groups. Univariable and multivariable Cox proportional hazards regression analyses were used to assess associations with ACM.

Results: We identified 42,192 patients diagnosed with testicular cancer between 2004 and 2013, with 280 having SCSTs and 41,912 patients having GCTs. Median age for SCSTs and GCTs was 45 (interquartile range [IQR] 34-59) and 34 (IQR 27-43), respectively $(p<0.001)$. Median follow-up was 39 and 52 months, respectively. Overall, patients with SCSTs had greater risk of ACM compared to those with GCTs (HR 1.69, 95\% Cl 1.14-2.50). Private insurance, greater education, and fewer comorbidities were associated with reduced risk of ACM ( $p<0.05$ for all). Among those with stage I disease, tumor type was not associated with ACM on multivariable analysis. Among those with stage II/III disease, patients with SCSTs had increased risk of ACM compared to patients with GCTs (HR 3.29, 95\% Cl 1.89-5.72).
\end{abstract}

Conclusions: Patients with advanced SCSTs had worse survival outcomes compared to those with advanced GCTs. These data suggest a need for further investigation to ascertain effective management recommendations for SCSTs.

Keywords: Testicular neoplasms, Leydig cell tumors, Sertoli cell tumors, Sex cord-gonadal stromal tumors, Testicular germ cell tumors

\footnotetext{
* Correspondence: kbz2102@columbia.edu

'Department of Urology, University of California, San Francisco, 550 16th

Street, 6th Floor, San Francisco, CA 94158, USA

${ }^{2}$ Osher Center for Integrative Medicine, University of California, San Francisco,

1545 Divisadero Street, Suite 301, San Francisco, CA 94143, USA

Full list of author information is available at the end of the article
}

(c) The Author(s). 2020 Open Access This article is licensed under a Creative Commons Attribution 4.0 International License, which permits use, sharing, adaptation, distribution and reproduction in any medium or format, as long as you give appropriate credit to the original author(s) and the source, provide a link to the Creative Commons licence, and indicate if changes were made. The images or other third party material in this article are included in the article's Creative Commons licence, unless indicated otherwise in a credit line to the material. If material is not included in the article's Creative Commons licence and your intended use is not permitted by statutory regulation or exceeds the permitted use, you will need to obtain permission directly from the copyright holder. To view a copy of this licence, visit http://creativecommons.org/licenses/by/4.0/. The Creative Commons Public Domain Dedication waiver (http://creativecommons.org/publicdomain/zero/1.0/) applies to the data made available in this article, unless otherwise stated in a credit line to the data. 


\section{Background}

Testicular cancer is a rare form of cancer, representing only $0.5 \%$ of new cancer cases in the United States (U.S.) [1]. It most commonly occurs in young adults, with 5.9 new cases per 100,000 men between 2012 and 2016 [1]. Testicular tumors can be further subclassified based on their cellular origin. Germ cell tumors (GCTs) account for roughly $95 \%$ of all testicular tumors and include seminomatous and nonseminomatous tumors (e.g., embryonal, mixed germ cell) [2]. Sex cord stromal tumors (SCSTs) make up the remaining 5\% of testicular tumors and include Leydig cell tumors (LCTs) and Sertoli cell tumors (SCTs) [3].

SCSTs and GCTs differ greatly in their biological aggressiveness and survival outcomes. GCTs have an excellent prognosis, with a 99.7\% 5-year disease-specific survival among those with Stage I tumors [4]. Patients with SCSTs appear to have worse survival outcomes, with the 5-year overall survival of patients with Stage I LCTs and SCTs being 91 and 77\%, respectively [5]. This survival difference is multifactorial, with the inherent aggressiveness of SCSTs, differences in patient characteristics, and variable response to treatment likely contributing to this finding [6-8]. Prior studies focused on SCSTs alone, primarily small series and case studies, have demonstrated worse disease-specific and overall survival outcomes, but few studies have directly compared outcomes between SCSTs and GCTs $[5,9,10]$. These studies have been predominantly limited by the rarity of these tumors and few mortality events reported in large national cancer registries [5, 9].

Given that the American Urological Association (AUA) provides formal guidelines for the management of GCTs but none specific to SCSTs, the management of SCSTs primarily reflects that of GCTs [11]. Thus, a survival comparison between these tumor types is critical to identify whether a need for guidelines specific to SCSTs is warranted. Using a large, nationwide database of cancer patients, we sought to compare total and stagespecific all-cause mortality (ACM) outcomes between patients with GCTs and SCTSs with consideration of multiple sociodemographic and clinical characteristics.

\section{Methods}

\section{Data source}

The NCDB is a nationwide, facility-based cancer registry started in 1989 as a joint program between the Commission on Cancer of the American College of Surgeons and the American Cancer Society. It encompasses over 1500 institutions and contains over $70 \%$ of all cancer diagnoses in the U.S. and Puerto Rico [12, 13]. This study was approved by the Institutional Review Board at the University of California, San Francisco.

\section{Patient selection}

Patients diagnosed between 2004 and 2013 were identified using the International Classification of Diseases for Oncology, Third Edition (ICD-O-3) codes for LCTs (8650), SCTs (8640), seminomas (9061), embryonal tumors (9070), and mixed germ cell tumors (9085). Diagnosis was determined from microscopic specimens, laboratory markers, imaging, or medical records from participating institutions. Those with unavailable staging information were excluded. Stage was defined by Clinical Stage Group or Clinical Pathological Group if the former was unavailable. Because of the low sample size of SCSTs, patients with stage II and stage III disease were collapsed into one group (stage II/III) for the survival analysis. We considered this a reasonable strategy, as both represent tumors that have spread beyond the testicle. Furthermore, this strategy has been performed in prior literature [5]. For the same reason, all forms of therapy received in addition to orchiectomy were grouped into an "adjuvant therapy" category. Of note, NCDB only reports first course treatments [14].

\section{Objectives and statistical analysis}

The primary endpoint was ACM. Demographic, clinicopathologic, and overall survival outcome data was collected. Survival time was calculated as the time in months between diagnosis and either death or last follow-up contact. Patient characteristics were compared using Pearson's chi-squared and Fischer's exact tests for categorical variables and Wilcoxon rank-sum tests for non-parametric continuous variables. Survival curves were generated using the Kaplan-Meier plot method. Log-rank test and Cox proportional hazard regression was used to compare differences in survival among the entire cohort and on subgroup analysis by tumor stage (stage I and stage II/III). The other variables included in the multivariable models included tumor type, diagnosis year, race/ethnicity, insurance type, annual household income, percent in the patient's ZIP code without a high school diploma, residential environment (metropolitan versus urban/ rural), and Charlson-Deyo comorbidity score (CDS). As the stage and adjuvant therapy variables violated the proportionality assumption, analyses were stratified on these variables (STATA 15 command: strata) [15]. The results are presented as hazard ratios (HR) with $95 \%$ confidence intervals (CI). HRs for patients with unknown values are not reported but were included in analyses to avoid selection bias secondary to elimination of those patients. A $p$-value $<0.05$ was considered statistically significant. Analyses were performed using STATA $15^{\circ}$. 


\section{Results}

\section{Sociodemographic and clinical characteristics between} groups

Forty-two thousand one hundred ninety-two patients diagnosed with testicular cancer between 2004 and 2013 were identified (Table 1). There were 45 patients with SCTs and 235 patients with LCTs for a total of 280 patients with SCSTs. There were 26,394 patients with seminomas, 11,358 patients with embryonal tumors, and 4160 patients with mixed germ cell tumors for a total of 41,912 patients with GCTs. Median follow-up time was 39 months (interquartile range [IQR] 20-61) for SCSTs and 52 months (IQR 28-79) for GCTs. Compared to patients with GCTs, patients with SCSTs tended to be older (45 years IQR 34-59 versus 34 years IQR 27-43, $p<0.001)$. Higher proportions of patients with SCSTs were non-Hispanic Black (17\% versus $3 \%$ ) and were on government insurance ( $25 \%$ versus $13 \%$ ) (all $p<0.001$ ). Higher proportions of patients with SCSTs had one or more comorbidities (10\% versus $6 \%, p=0.001)$ and had stage I disease at diagnosis (93\% versus $77 \%, p<0.001$ ). A considerably lower proportion of patients with SCSTs received adjuvant therapy in addition to orchiectomy $(6 \%$ versus $56 \%, \mathrm{p}<0.001)$. Type of adjuvant therapy received in addition to orchiectomy by tumor type can be seen in Supplementary Table 1.

The aforementioned observations remained true when broken down by stage with a few exceptions (Table 2). There was no statistically significant difference in race/ ethnic distribution or insurance status among those with advanced disease. Notably, among those with advanced disease, the magnitude of difference of the proportion of those with one or more comorbidities was greater among those with SCSTs $(29 \%$ versus $7 \%, p<0.001)$.

\section{Survival analysis}

On multivariable Cox proportional hazards regression of the overall group, patients with SCSTs had greater risk of ACM compared to those with GCTs (HR 1.68, 95\% CI 1.13-2.49, $p=0.010$ ) (Table 3) on multivariable analysis adjusting for stage and treatment via stratification. Compared to those with private insurance, those who were uninsured (HR 2.31, 95\% CI 2.01-2.66, $p<0.001$ ) or who had government insurance (HR 2.72, 95\% CI 2.42-3.05, $\mathrm{p}<0.001$ ) had greater risk of ACM. Having one or more comorbidities also conferred a greater risk of ACM (HR 2.06, 95\% CI 1.79-2.37, p < 0.001).

The Kaplan-Meier curves comparing overall survival outcomes between tumors types by stage can be seen in Fig. 1. At 1, 2, and 5 years, the overall survival rates for stage I SCSTs was 99\% (95\% CI 96-100\%), 96\% (95\% CI 92-98\%), and 94\% (95\% CI 89-97\%), respectively and for stage I GCTs was 99\% (95\% CI 99-100\%), 99\% (95\% CI 99-99\%), and 97\% (95\% CI 97-98\%), respectively
Table 1 Overall comparison of the sociodemographic and clinical characteristics of patients with SCSTs versus GCTs

\begin{tabular}{|c|c|c|c|c|}
\hline Factor & Overall cohort & SCSTS & GCTs & $p$-value \\
\hline $\mathrm{N}$ & 42,192 & 280 & 41,912 & \\
\hline $\begin{array}{l}\text { Age at diagnosis, } \\
\text { median (IQR) }\end{array}$ & $34(27,43)$ & $45(34,59)$ & $34(27,43)$ & $<0.001$ \\
\hline Diagnosis year & & & & 0.002 \\
\hline 2004-2005 & $8215(20 \%)$ & $48(17 \%)$ & $8167(20 \%)$ & \\
\hline 2006-2007 & $8329(20 \%)$ & $39(14 \%)$ & $8290(20 \%)$ & \\
\hline 2008-2009 & $8520(20 \%)$ & $50(18 \%)$ & $8470(20 \%)$ & \\
\hline 2010-2011 & $8561(20 \%)$ & $81(29 \%)$ & $8480(20 \%)$ & \\
\hline 2012-2013 & $8567(20 \%)$ & $62(22 \%)$ & $8505(20 \%)$ & \\
\hline Race/ethnicity & & & & $<0.001$ \\
\hline Non-Hispanic White & 32,565 (77\%) & $174(62 \%)$ & $32,391(77 \%)$ & \\
\hline Non-Hispanic Black & $1168(3 \%)$ & $48(17 \%)$ & $1120(3 \%)$ & \\
\hline Hispanic/Other & $7727(18 \%)$ & $55(20 \%)$ & $7672(18 \%)$ & \\
\hline Unknown & $732(2 \%)$ & $3(1 \%)$ & $729(2 \%)$ & \\
\hline Insurance & & & & $<0.001$ \\
\hline Uninsured & $4786(11 \%)$ & $24(9 \%)$ & $4762(11 \%)$ & \\
\hline Private insurance & $31,092(74 \%)$ & $178(64 \%)$ & 30,914 (74\%) & \\
\hline $\begin{array}{l}\text { Medicaid/Medicare } \\
\text { /other } \\
\text { government insurance }\end{array}$ & $5487(13 \%)$ & $70(25 \%)$ & $5417(13 \%)$ & \\
\hline Unknown & $827(2 \%)$ & $8(3 \%)$ & $819(2 \%)$ & \\
\hline Income (per year) & & & & 0.42 \\
\hline Less than $\$ 38 \mathrm{k}$ & $5533(13 \%)$ & $45(16 \%)$ & $5488(13 \%)$ & \\
\hline$\$ 38 k-62,999$ & $20,324(48 \%)$ & 125 (45\%) & $20,199(48 \%)$ & \\
\hline$\$ 63 \mathrm{k}$ or greater & 15,769 (37\%) & $106(38 \%)$ & $15,663(37 \%)$ & \\
\hline Unknown & $566(1 \%)$ & $4(1 \%)$ & $562(1 \%)$ & \\
\hline
\end{tabular}

Percent in ZIP code without a high school degree

$21 \%$ or greater
$7-20.9 \%$
Less than $7 \%$
Unknown

Residence

Metropolitan

Urban/rural

Charlson-Deyo

comorbidity score

0

1 or more

Stage

Stage I

Stage II

Stage III

Treatment received

No orchiectomy

Orchiectomy alone

Orchiectomy +

adjuvant therapy

$\begin{array}{lll}6203(15 \%) & 42(15 \%) & 6161(15 \%) \\ 23,172(55 \%) & 159(57 \%) & 23,013(55 \%) \\ 12,287(29 \%) & 75(27 \%) & 12,212(29 \%) \\ 530(1 \%) & 4(1 \%) & 526(1 \%)\end{array}$

$35,048(83 \%) \quad 237(85 \%) \quad 34,811(83 \%)$ $7144(17 \%) \quad 43(15 \%) \quad 7101(17 \%)$

39,825 (94\%) $252(90 \%) \quad 39,573(94 \%)$

2367 (6\%)

$28(10 \%)$

$2339(6 \%)$

$32,463(77 \%) \quad 259(93 \%) \quad 32,204(77 \%)$

$5478(13 \%) \quad 9(3 \%) \quad 5469(13 \%)$

$4251(10 \%) \quad 12(4 \%) \quad 4239(10 \%)$
17,885 (42\%) 260 (93\%) 17,625 (42\%)

$23,585(56 \%) \quad 18(6 \%) \quad 23,567(56 \%)$ 
Table 1 Overall comparison of the sociodemographic and clinical characteristics of patients with SCSTs versus GCTs (Continued)

\begin{tabular}{lllll}
\hline Factor & Overall cohort & SCSTs & GCTs & $p$-value \\
\hline \multicolumn{1}{c}{ Other/unknown } & $56(0.1 \%)$ & $0(0 \%)$ & $56(0.1 \%)$ & \\
$\begin{array}{l}\text { Last contact or death, } \\
\text { months from diagnosis, }\end{array}$ & $N=37,716$ & $N=249$ & $\mathrm{~N}=37,467$ & \\
$\begin{array}{l}\text { median (IQR) } \\
\text { Time from diagnosis }\end{array}$ & $N=1640$ & $N=27$ & $N=1613$ & \\
$\begin{array}{l}\text { to death in months, } \\
\text { median (IQR) }\end{array}$ & $20(7,43)$ & $18(7,37)$ & $20(7,43)$ & 0.88 \\
\hline
\end{tabular}

GCTs Germ cell tumors, IQR Interquartile range, SCSTs Sex cord stromal tumors

(log-rank $p<0.001)$. Among those with stage I disease, tumor type was not associated with ACM on multivariable analysis (Table 4). High income (HR 0.74 among those making $>\$ 63,000 /$ year compared to those making $<\$ 38,000 /$ year, $95 \%$ CI $0.56-0.98, p=0.032$ ), was associated with lower ACM.

At 1,2, and 5 years, the overall survival rates for stage II/III SCSTs was 60\% (95\% CI 36-78\%), 44\% (95\% CI $22-64 \%$ ), and $25 \%$ (95\% CI 8-47\%), respectively and for stage II/III GCTs was 95\% (95\% CI 95-96\%), 92\% (95\% CI 92-93\%), and 89\% (95\% CI 88-90\%) (log-rank $p<$ 0.001). Among those with stage II/III disease, those with SCSTs had a statistically significantly increased risk of ACM (HR 3.28, 95\% CI 1.88-5.73, $p<0.001$ ) on multivariable analysis adjusting for treatment via stratification (Table 4). Percent of individuals in the patient's ZIP code without a high school diploma (HR 0.67 for $<7 \%$ compared to $>21,95 \%$ CI $0.52-0.89, p=0.004$ ) was associated with ACM.

\section{Discussion}

Using a national registry of testicular cancer patients, we found that SCSTs conferred increased risk of ACM compared to patients with GCT. However, on multivariable subgroup analysis, this difference in overall survival was limited to those with advanced (stage II/III) disease. For these patients, the risk of ACM in the SCST group was more than three times greater than that of the GCT group. We also found that patients with SCSTs tended to be older and were more frequently of Black race.

The association between SCSTs and worse survival outcomes has been shown previously. Osbun et al. used the Surveillance, Epidemiology, and End Results (SEER) program database to estimate cancer-specific mortality (CSM) for various testicular tumor types. They found a lower overall CSM among patients with GCTs (2\%) compared to those with LCTs $(7 \%)$ or SCTs $(32 \%, p<$ 0.001) [9]. They also reported an observation of higher unadjusted CSM rates in patients with SCSTs both in stage I and stage III disease. As with our population, higher proportions of SEER patients with SCSTs were older and Black; however, in contrast to our population, a higher proportion of SEER patients with SCSTs presented with advanced disease.

The finding that there is a greater risk of ACM with SCSTs versus GCTs among patients with advanced disease regardless of receipt of adjuvant therapy use indicates that management recommendations specific to SCSTs are needed. Currently, the AUA provides guidelines for the management of seminomatous and nonseminomatous GCTs but does not specifically address SCSTs [11]. Thus, much of the management reflects that of GCTs. An initial approach of radical resection for early stage disease has been shown to be effective $[6,16]$. Featherstone et al. reported that, among 36 patients with SCSTs treated with orchiectomy alone, none progressed to metastatic disease after a minimum follow-up period of 2 years [16]. These results are consistent with the high overall survival among patients with stage I disease, and perhaps translation of management of SCSTs from that of GCTs is appropriate.

Using GCTs as a reference, our data suggests that patients with disseminated SCSTs do not experience the same relatively high overall survival rates as those with localized disease. Although surgical management via retroperitoneal lymphadenectomy may have modest efficacy in those with established nodal disease, traditional chemotherapy regimens used to treat GCTs like bleomycin, etoposide, and cisplatin (BEP) or vinblastine, ifosfamide, and cisplatin (VIP) have demonstrated a transient response in SCSTs [6-8]. Radiotherapy also appears to be ineffectual for these tumors $[8,17]$. This lack of effectiveness signals an opportunity to investigate the potency of newer chemotherapeutics, hormonal therapies, and immunologic agents to improve outcomes for patients with this rare tumor type. For example, it has been demonstrated that glucocorticoid treatment may inhibit a hormone-mediated cell growth mechanism in LCTs that leads to tumor regression in murine models [18]. Imatinib, a selective tyrosine kinase inhibitor, has been shown to decrease viability of Leydig tumor cell lines [19]. Furthermore, with the advent of the use of genomics and precision medicine, future therapeutic regimens could potentially be tailored for these patients and may help improve treatment outcomes in patients with advanced disease [20]. Necchi et al. performed comprehensive genome profiling on the tumors of 10 patients with metastatic SCSTs and reported that, although uncommon, several tumors expressed targetable genomic alterations indicating the potential efficacy of cell-cycle, mTOR, hedgehog, and polymerase inhibitors [20]. A case-series by Calaway et al. reported that two patients with disseminated SCSTs had tumor genetic susceptibility testing following retroperitoneal lymph 
Table 2 Stage-specific comparison of the sociodemographic and clinical characteristics of patients with SCSTs versus GCTs

\begin{tabular}{|c|c|c|c|c|c|c|}
\hline \multirow[t]{2}{*}{ Factor } & \multicolumn{2}{|l|}{ Stage I } & \multirow[b]{2}{*}{$p$-value } & \multicolumn{2}{|l|}{ Stage $\|/\| \|$} & \multirow[b]{2}{*}{ p-value } \\
\hline & $\overline{\mathrm{SCSTS}}$ & GCTs & & $\overline{\text { SCSTS }}$ & GCTs & \\
\hline $\mathrm{N}$ & 259 & 32,204 & & 21 & 9708 & \\
\hline Age at diagnosis, median (IQR) & $43(34,57)$ & $34(28,43)$ & $<0.001$ & $55(42,64)$ & $33(26,42)$ & $<0.001$ \\
\hline Diagnosis year & & & $<0.001$ & & & 0.38 \\
\hline 2004-2005 & $46(18 \%)$ & $6387(20 \%)$ & & $2(10 \%)$ & $1780(18 \%)$ & \\
\hline $2006-2007$ & $33(13 \%)$ & $6416(20 \%)$ & & $6(29 \%)$ & $1874(19 \%)$ & \\
\hline $2008-2009$ & $45(17 \%)$ & $6528(20 \%)$ & & $5(24 \%)$ & $1942(20 \%)$ & \\
\hline 2010-2011 & 75 (29\%) & $6487(20 \%)$ & & $6(29 \%)$ & $1993(21 \%)$ & \\
\hline 2012-2013 & $60(23 \%)$ & $6386(20 \%)$ & & $2(10 \%)$ & $2119(22 \%)$ & \\
\hline Race/ethnicity & & & $<0.001$ & & & 0.62 \\
\hline Non-Hispanic White & $157(61 \%)$ & $25,125(78 \%)$ & & $17(81 \%)$ & $7266(75 \%)$ & \\
\hline Non-Hispanic Black & $47(18 \%)$ & $809(3 \%)$ & & $1(5 \%)$ & $311(3 \%)$ & \\
\hline Hispanic/Other & $52(20 \%)$ & $5672(18 \%)$ & & $3(14 \%)$ & $2000(21 \%)$ & \\
\hline Unknown & $3(1 \%)$ & $598(2 \%)$ & & $0(0 \%)$ & 131 (1\%) & \\
\hline Insurance & & & $<0.001$ & & & 0.087 \\
\hline Uninsured & 169 (65\%) & 3411 (11\%) & & $4(19 \%)$ & $1351(14 \%)$ & \\
\hline Private insurance & $20(8 \%)$ & 24,575 (76\%) & & $9(43 \%)$ & $6339(65 \%)$ & \\
\hline $\begin{array}{l}\text { Medicaid/Medicare/other } \\
\text { government insurance }\end{array}$ & $62(24 \%)$ & 3605 (11\%) & & $8(38 \%)$ & 1812 (19\%) & \\
\hline Unknown & $8(3 \%)$ & $613(2 \%)$ & & $0(0 \%)$ & $206(2 \%)$ & \\
\hline Income (per year) & & & 0.38 & & & 0.68 \\
\hline Less than $\$ 38 \mathrm{k}$ & 40 (15\%) & 3981 (12\%) & & $5(24 \%)$ & 1507 (16\%) & \\
\hline$\$ 38 k-62,999$ & 115 (44\%) & 15,408 (48\%) & & $10(48 \%)$ & 4791 (49\%) & \\
\hline$\$ 63 \mathrm{k}$ or greater & 100 (39\%) & 12,407 (39\%) & & $6(29 \%)$ & $3256(34 \%)$ & \\
\hline Unknown & $4(2 \%)$ & 408 (1\%) & & $0(0 \%)$ & $154(2 \%)$ & \\
\hline $\begin{array}{l}\text { Percent in ZIP code without a high } \\
\text { school degree }\end{array}$ & & & 0.69 & & & 0.75 \\
\hline $21 \%$ or greater & $37(14 \%)$ & 4450 (14\%) & & $5(24 \%)$ & $1711(18 \%)$ & \\
\hline $7-20.9 \%$ & 147 (57\%) & $17,658(55 \%)$ & & $12(57 \%)$ & $5355(55 \%)$ & \\
\hline Less than $7 \%$ & 71 (27\%) & $9716(30 \%)$ & & $4(19 \%)$ & $2496(26 \%)$ & \\
\hline Unknown & $4(2 \%)$ & $380(1 \%)$ & & $0(0 \%)$ & $146(2 \%)$ & \\
\hline Residence & & & 0.42 & & & 0.51 \\
\hline Metropolitan & $221(85 \%)$ & 26,877 (84\%) & & $16(76 \%)$ & 7934 (82\%) & \\
\hline Urban/rural & $38(15 \%)$ & $5327(17 \%)$ & & $5(24 \%)$ & $1774(18 \%)$ & \\
\hline Charlson-Deyo comorbidity score & & & 0.016 & & & $<0.001$ \\
\hline 0 & 237 (92\%) & $30,544(95 \%)$ & & $15(71 \%)$ & $9029(93 \%)$ & \\
\hline 1 or more & $22(9 \%)$ & $1660(5 \%)$ & & $6(29 \%)$ & $679(7 \%)$ & \\
\hline Stage & & & & & & 0.21 \\
\hline Stage I & $259(100 \%)$ & $32,204(100 \%)$ & & - & - & \\
\hline Stage II & - & - & & $9(43 \%)$ & $5469(56 \%)$ & \\
\hline Stage III & - & - & & $12(57 \%)$ & $4239(44 \%)$ & \\
\hline Treatment & & & $<0.001$ & & & $<0.001$ \\
\hline No orchiectomy & $0(0 \%)$ & $30(0.1 \%)$ & & $2(10 \%)$ & $634(7 \%)$ & \\
\hline Orchiectomy alone & $250(97 \%)$ & $16,519(51 \%)$ & & $10(48 \%)$ & $1106(11 \%)$ & \\
\hline Orchiectomy + adjuvant therapy & $9(4 \%)$ & $15,626(49 \%)$ & & $9(43 \%)$ & $7941(82 \%)$ & \\
\hline
\end{tabular}


Table 2 Stage-specific comparison of the sociodemographic and clinical characteristics of patients with SCSTs versus GCTs (Continued)

\begin{tabular}{|c|c|c|c|c|c|c|}
\hline \multirow[t]{2}{*}{ Factor } & \multicolumn{2}{|l|}{ Stage I } & \multirow[b]{2}{*}{ p-value } & \multicolumn{2}{|l|}{ Stage $\|/\| I \|$} & \multirow[b]{2}{*}{$p$-value } \\
\hline & SCSTs & GCTs & & SCSTs & GCTs & \\
\hline Other/unknown & $0(0 \%)$ & $29(0.1 \%)$ & & $0(0 \%)$ & $27(0.3 \%)$ & \\
\hline \multirow{2}{*}{$\begin{array}{l}\text { Last contact or death, months from } \\
\text { diagnosis, median (IQR) }\end{array}$} & $N=229$ & $N=28,855$ & $<0.001$ & $N=20$ & $N=8612$ & 0.002 \\
\hline & $41(22,62)$ & $53(29,80)$ & & $19(8,55)$ & $47(24,75)$ & \\
\hline \multirow[t]{2}{*}{ Time from diagnosis to death, median (IQR) } & $N=13$ & $N=747$ & & $N=14$ & $N=866$ & \\
\hline & $23(18,43)$ & $31(14,58)$ & 0.78 & $11(7,21)$ & $13(4,28)$ & 0.96 \\
\hline
\end{tabular}

GCTs Germ cell tumors, IQR Interquartile range, SCSTs Sex cord stromal tumors

Table 3 Univariable and multivariable Cox proportional hazards regression analysis on the association between sociodemographic and clinical characteristics and mortality of the overall cohort

\begin{tabular}{|c|c|c|}
\hline & Univariable HR (95\% Cl) & Multivariable ${ }^{a} \mathrm{HR}(95 \% \mathrm{CI})$ - Overall \\
\hline \multicolumn{3}{|l|}{ Tumor type } \\
\hline GCTs & Ref. & Ref. \\
\hline SCSTs & $2.96(2.03-4.33)^{* * *}$ & $1.68(1.13-2.49)^{*}$ \\
\hline Age (per 5-year increase) & $1.21(1.19-1.23)^{* * *}$ & $1.18(1.16-1.20)^{* * *}$ \\
\hline \multicolumn{3}{|l|}{ Race/ethnicity } \\
\hline Non-Hispanic White & Ref. & Ref. \\
\hline Non-Hispanic Black & $1.80(1.41-2.29)^{* * *}$ & $1.13(0.89-1.45)$ \\
\hline Hispanic/other & $1.27(1.13-1.43)^{* * *}$ & $1.14(1.01-1.30)^{*}$ \\
\hline \multicolumn{3}{|l|}{ Insurance } \\
\hline Private insurance & Ref. & Ref. \\
\hline Uninsured & $2.63(2.29-3.01)^{* * *}$ & $2.32(2.01-2.66)^{* * *}$ \\
\hline Medicaid/Medicare/other government insurance & $4.33(3.88-4.83)^{* * *}$ & $2.72(2.42-3.05)^{* * *}$ \\
\hline \multicolumn{3}{|l|}{ Income (per year) } \\
\hline$<\$ 38,000$ & Ref. & Ref. \\
\hline$\$ 38,000-\$ 62,999$ & $0.71(0.62-0.81)^{* * *}$ & $0.94(0.82-1.09)$ \\
\hline$>\$ 63,000$ & $0.44(0.38-0.50)^{* * *}$ & $0.76(0.63-0.92)^{* *}$ \\
\hline \multicolumn{3}{|l|}{ Percent in ZIP code without a high school diploma } \\
\hline$>21 \%$ & Ref. & Ref. \\
\hline $7-20.9 \%$ & $0.63(0.56-0.71)^{* * *}$ & $0.83(0.73-0.96)^{*}$ \\
\hline$<7 \%$ & $0.43(0.37-0.49)^{* * *}$ & $0.74(0.61-0.90)^{* *}$ \\
\hline \multicolumn{3}{|l|}{ Residence } \\
\hline Metropolitan & Ref. & Ref. \\
\hline Urban/rural & $1.49(1.33-1.67)^{* * * *}$ & $1.13(1.00-1.28)$ \\
\hline \multicolumn{3}{|l|}{ Charlson-Deyo comorbidity score } \\
\hline 0 & Ref. & Ref. \\
\hline$\geq 1$ & $3.23(2.82-3.70)^{* * *}$ & $2.06(1.79-2.37)^{* * *}$ \\
\hline
\end{tabular}

CI Confidence interval, GCTs Germ cell tumors, HR Hazard ratio, IQR Interquartile range, SCSTs Sex cord stromal tumors

${ }^{*} p<0.05$

** $p<0.01$

***p $<0.001$

aThe following variables were included in the multivariable analysis: tumor type, age, diagnosis year, race/ethnicity, insurance, yearly income, percent in ZIP code without a high school diploma, residence, Charlson-Deyo comorbidity score 
a)

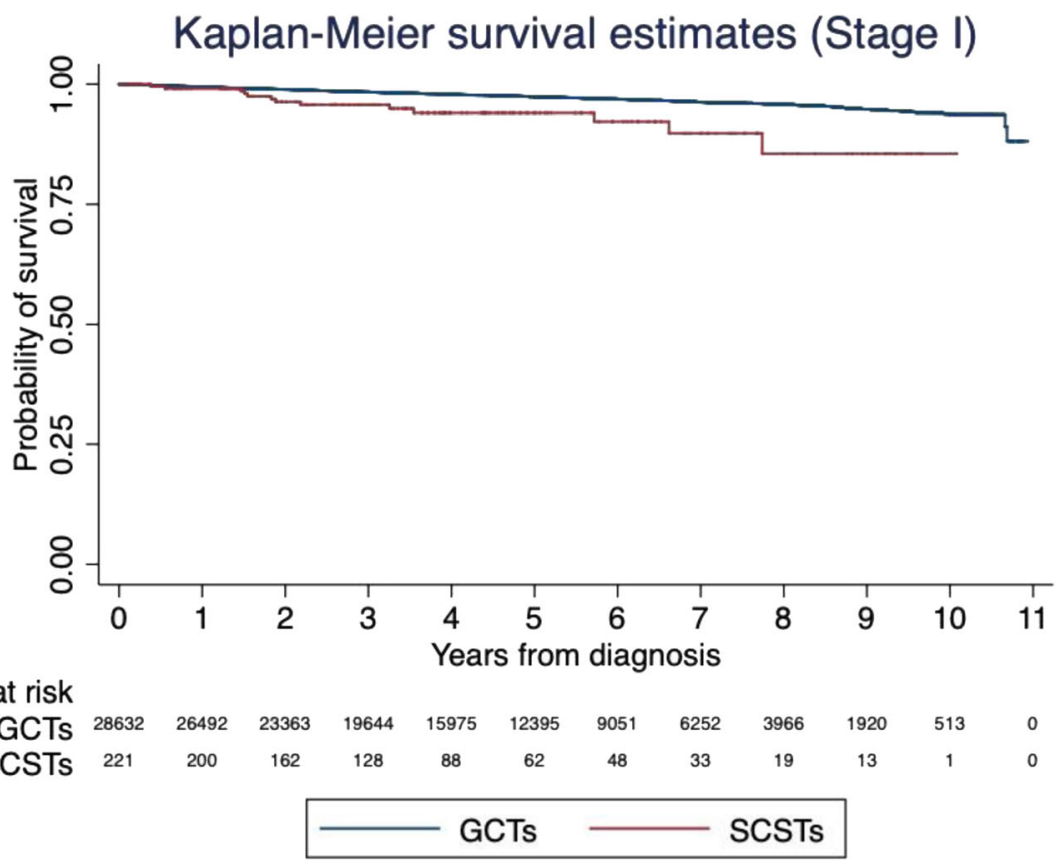

b)

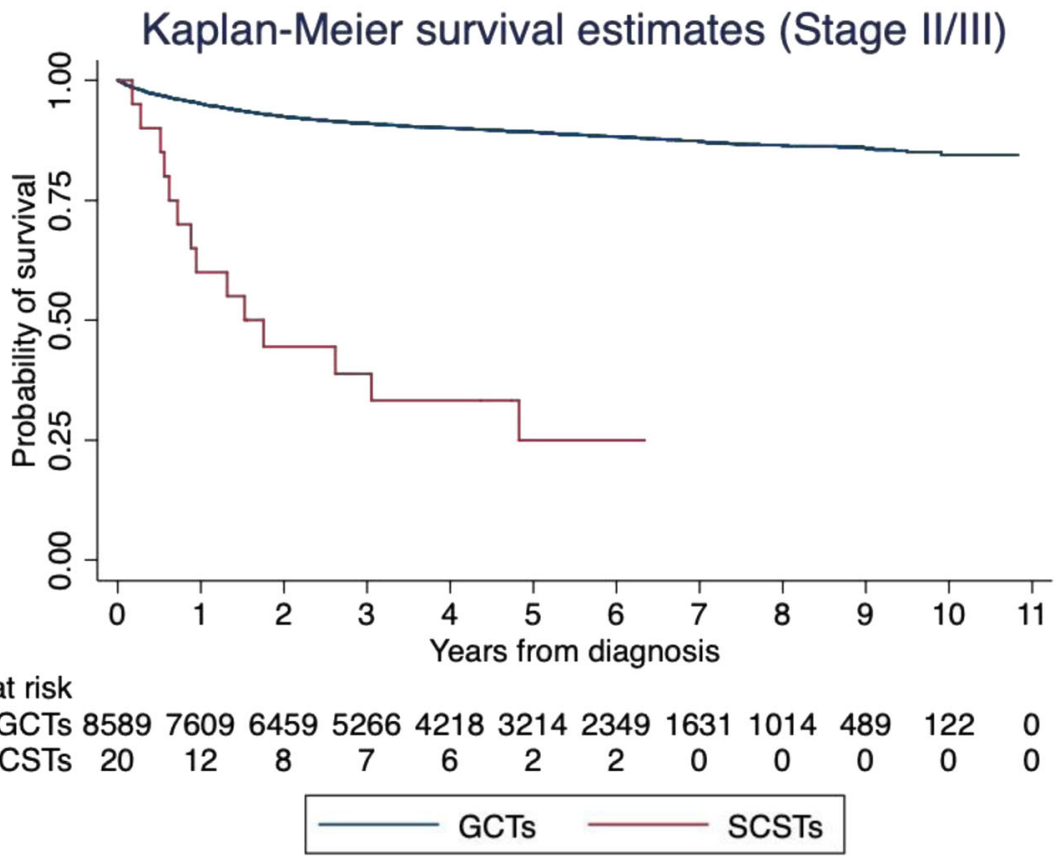

Fig. 1 Kaplan-Meier survival estimates comparing all-cause mortality between patients with SCSTs versus GCTs among those with a) stage I disease and $\mathbf{b}$ ) stage $I / / \| l$ disease

node dissection. At the time of publication, one patient was surviving on apalutamide for 4 months and another was on everolimus with slightly regressing metastatic disease for 12 months [21]. Finally, a step further would be to enhance methods for distinguishing malignant from benign LCTs for more directed adjuvant treatments.
This study is not without limitations. The inclusion of patients in this study assumes accurate designation of ICD-O-3 coding by providers and misclassification may bias the findings. This dataset also relies upon accurate reporting of histology, as there is no central pathology review. The NCDB has limited information on treatment specifics (e.g., type of chemotherapeutic agent), schedule 
Table 4 Multivariable Cox proportional hazards regression analysis on the association between sociodemographic and clinical characteristics and mortality by stage

Multivariable $^{a} \mathrm{HR} \quad$ Multivariable $^{\mathrm{a}} \mathrm{HR}$

$(95 \% \mathrm{Cl})$ - Stage I $\quad(95 \% \mathrm{Cl})-$ Stage II/III

\section{Tumor type}

$\begin{array}{cll}\text { GCTs } & \text { Ref. } & \text { Ref. } \\ \text { SCSTs } & 1.06(0.60-1.86) & 3.28(1.88-5.73)^{* * *} \\ \text { Age (per 5-year increase) } & 1.23(1.20-1.26)^{* * *} & 1.13(1.10-1.16)^{* * *}\end{array}$

Race/ethnicity

$\begin{array}{lll}\text { Non-Hispanic White } & \text { Ref. } & \text { Ref. } \\ \text { Non-Hispanic Black } & 1.18(0.80-1.72) & 1.13(0.81-1.56) \\ \text { Hispanic/other } & 1.14(0.95-1.38) & 1.12(0.94-1.32)\end{array}$

Insurance

$\begin{array}{lll}\text { Private insurance } & \text { Ref. } & \text { Ref. } \\ \text { Uninsured } & 2.58(2.08-3.21)^{* * *} & 2.07(1.72-2.50)^{* * *} \\ \begin{array}{l}\text { Medicaid/Medicare/other } \\ \text { government insurance }\end{array} & 3.15(2.64-3.75)^{* * *} & 2.31(1.97-2.70)^{* * *}\end{array}$

Income (per year)

$\begin{array}{lll}<\$ 38,000 & \text { Ref. } & \text { Ref. } \\ \$ 38,000-\$ 62,999 & 0.92(0.74-1.15) & 0.96(0.79-1.16) \\ >\$ 63,000 & 0.74(0.56-0.98)^{*} & 0.77(0.61-1.02)\end{array}$

Percent in ZIP code without a high school diploma

$\begin{array}{lll}>21 \% & \text { Ref. } & \text { Ref. } \\ 7-20.9 \% & 0.87(0.70-1.07) & 0.80(0.67-0.97)^{*} \\ <7 \% & 0.80(0.61-1.06) & 0.68(0.52-0.88)^{* *} \\ \text { Residence } & & \\ \text { Metropolitan } & \text { Ref. } & \text { Ref. } \\ \text { Urban/rural } & 1.18(0.98-1.42) & 1.09(0.91-1.29)\end{array}$

Charlson-Deyo comorbidity score

\begin{tabular}{lll}
0 & Ref. & Ref. \\
$\geq 1$ & $2.03(1.64-2.51)^{* * *}$ & $2.03(1.68-2.45)^{* * *}$ \\
\hline
\end{tabular}

${ }^{a}$ The following variables were included in the multivariable analysis: tumor type, age, diagnosis year, race/ethnicity, insurance, yearly income, percent in ZIP code without a high school diploma, residence, Charlson-Deyo comorbidity score

and sequence of treatment cycles, and does not provide information on CSM. Despite these limitations, for those with advanced disease the differences between ACM and CSM rates are reduced. Additionally, the NCDB does not contain information that may influence quality of care received (e.g., hospital quality, surgeon experience, patient healthcare access/literacy, etc.); however, many factors that contribute to this (e.g., income, insurance, education) were controlled for in our analysis. As this study is a retrospective study based on an observational dataset, there are unmeasured confounders which could impact these findings. In addition, the small sample size of SCSTs limited multivariable comparisons of ACM between SCST subtypes, and it has been proposed that
LCTs and SCTs may confer different degrees of ACM risk [5]. The small sample size also precluded analysis by adjuvant treatment type, which would help provide more actionable data on the most effective management strategy for these tumors. Along those same lines, our conclusion of survival differences between patients with advanced SCSTs versus advanced GCTs is based on just 21 SCST patients. Despite its comparison to a large group of GCT patients, this may limit the accuracy of our conclusions and warrants future studies with larger populations of SCST patients. The greater proportion of stage III patients in the SCST group versus the GCT group may have had an influence on survival; however, the absolute difference between groups was quite small. Additionally, the older age and greater proportion of patients with 1 or more comorbidity among those with advanced SCSTs could have been confounders in our survival analysis; however, these differences should have been controlled for in the multivariable model. Despite these limitations, this study presents novel data comparing testicular tumors types among a large number of patients with multiple sociodemographic and clinical variables considered, and its findings may have important implications in altering management practices.

\section{Conclusions}

Among this cohort, when comparing SCSTs to GCTs, patients with stage II/III disease but not stage I disease was associated with a statistically significantly increased risk of ACM on multivariable analysis. Increased ACM in patients with advanced SCSTs indicates an imperative for targeted treatment regimens specific to this unique tumor type.

\section{Supplementary information}

Supplementary information accompanies this paper at https://doi.org/10. 1186/s12894-020-00609-2.

Additional file 1: Table S1. Comparison of therapy received in addition to orchiectomy among patients with SCSTs versus GCTS.

\section{Abbreviations}

ACM: All-Cause Mortality; AUA: American Urological Association; BEP: Bleomycin, Etoposide, and Cisplatin; CDS: Charleson-Deyo comorbidity score; Cl: Confidence Interval; CSM: Cancer-Specific Mortality; GCT: Germ Cell Tumor; HR: Hazard Ratio; ICD-O-3: International Classification of Diseases for Oncology, Third Edition; IQR: Interquartile Range; LCT: Leydig Cell Tumor; SCT: Sertoli Cell Tumor; SCST: Sex Cord Stromal Tumor; SEER: Surveillance, Epidemiology, and End Results; U.S.: United States; VIP: Vinblastine, Ifosfamide, and Cisplatin

Acknowledgements

We are grateful to Janet Cowan for assistance in preparation of this manuscript.

Declarations of interest

None. 


\section{Authors' contributions}

KBZ, SLW, SPP, and MVM made substantial contributions to the design of this work. KBZ and SLW analysed the data. KBZ, SLW, SPP and MVM interpreted the data. KBZ drafted the work. KBZ, SLW, SPP, and MVM substantially revised the work. All authors have read and approved the manuscript.

\section{Funding}

KBZ, responsible for data analysis, data interpretation, and manuscript drafting, was supported by the National Center for Complementary and Integrative Health [T32AT003997].

\section{Availability of data and materials}

The datasets generated and/or analysed during the current study are available in the National Cancer Database repository:

https://www.facs.org/quality-programs/cancer/ncdb

\section{Ethics approval and consent to participate}

This study was approved by the Institutional Review Board at the University of California, San Francisco. There are no administrative permissions or licenses to access the data to formally note.

\section{Consent for publication}

Not applicable.

\section{Competing interests}

The authors declare that they have no competing interests relevant to this manuscript.

\section{Author details}

'Department of Urology, University of California, San Francisco, 550 16th Street, 6th Floor, San Francisco, CA 94158, USA. ${ }^{2}$ Osher Center for Integrative Medicine, University of California, San Francisco, 1545 Divisadero Street, Suite 301, San Francisco, CA 94143, USA. ${ }^{3}$ Vagelos College of Physicians and Surgeons, Columbia University Medical Center, 630 West 168th Street, New York, NY 10032, USA.

Received: 24 October 2019 Accepted: 3 April 2020

Published online: 17 April 2020

\section{References}

1. National Institutes of Health; National Cancer Institute; Surveillance, Epidemiology, and End Results Program: Cancer Stat Facts: Testicular Cancer. Available at https://seercancergov/statfacts/html/testis.html. Accessed 16 May 2019.

2. Bosl GJ, Motzer RJ. Testicular germ-cell Cancer. N Engl J Med. 1997;337(4): 242-54.

3. Dilworth JP, Farrow GM, Oesterling JE. Non-germ cell tumors of testis. Urology. 1991;37(5):399-417.

4. Kollmannsberger C, Tandstad T, Bedard PL, Cohn-Cedermark G, Chung PW, Jewett MA, et al. Patterns of relapse in patients with clinical stage I testicular cancer managed with active surveillance. J Clin Oncol. 2015; 33(1):51-7.

5. Banerij JS, Odem-Davis K, Wolff EM, Nichols CR, Porter CR. Patterns of care and survival outcomes for malignant sex cord stromal testicular Cancer: results from the National Cancer Data Base. J Urol. 2016;196(4):1117-22.

6. Nicolai N, Necchi A, Raggi D, Biasoni D, Catanzaro M, Piva L, et al. Clinical outcome in testicular sex cord stromal tumors: testis sparing vs. radical orchiectomy and management of advanced disease. Urology. 2015;85(2): 402-6.

7. Mosharafa AA, Foster RS, Bihrle R, Koch MO, Ulbright $T M$, Einhorn $L H$, et al. Does retroperitoneal lymph node dissection have a curative role for patients with sex cord-stromal testicular tumors? Cancer. 2003;98(4):753-7.

8. Bertram KA, Bratloff B, Hodges GF, Davidson H. Treatment of malignant leydig cell tumor. Cancer. 1991;68(10):2324-9.

9. Osbun N, Winters B, Holt SK, Schade GR, Lin DW, Wright JL. Characteristics of patients with Sertoli and Leydig cell testis neoplasms from a National Population-Based Registry. Clin Genitourin Cancer. 2017;15(2):e263-e6.

10. Kamran SC, Seisen T, Markt SC, Preston MA, Trinh QD, Frazier LA, et al. Contemporary treatment patterns and outcomes for clinical stage is testicular Cancer. Eur Urol. 2018;73(2):262-70.
11. Stephenson A, Eggener SE, Bass EB, Chelnick DM, Daneshmand S, Feldman D, et al. Diagnosis And Treatment Of Early Stage Testicular Cancer: Aua Guideline. J Urol. 2019;202(2):272-81. https://doi.org/10.1097/JU. 0000000000000318.

12. Raval MV, Bilimoria KY, Stewart AK, Bentrem DJ, Ko CY. Using the NCDB for cancer care improvement: an introduction to available quality assessment tools. J Surg Oncol. 2009;99(8):488-90.

13. American College of Surgeons; National Cancer Database: About the National Cancer Database Avalable at https://www.facs.org/qualityprograms/cancer/ncdb/about Accessed 15 May 2019.

14. American College of Surgeons; National Cancer Database: National Cancer Data Base Participant User File (PUF) Data Dictionary Version: PUF 2016 Available at https://www.facs.org/ /media/files/quality\%20programs/cancer/ ncdb/puf_data_dictionary.ashx Accessed 20 May 2019.

15. Pitblado J. Survey data analysis in Stata. 2009. https://www.stata.com/ meeting/canada09/ca09_pitblado_handout.pdf.

16. Featherstone JM, Fernando HS, Theaker JM, Simmonds PD, Hayes MC, Mead GM. Sex cord stromal testicular tumors: a clinical series--uniformly stage I disease. J Urol. 2009;181(5):2090-6 discussion 6.

17. Sawin PD, VanGilder JC. Spinal cord compression from metastatic Leydig's cell tumor of the testis: case report. Neurosurgery. 1996;38(2):407-11.

18. Panza S, Malivindi R, Chemi F, Rago V, Giordano C, Barone I, et al. Glucocorticoid receptor as a potential target to decrease aromatase expression and inhibit Leydig tumor growth. Am J Pathol. 2016;186(5):1328-39.

19. Basciani S, Brama M, Mariani S, De Luca G, Arizzi M, Vesci L, et al. Imatinib mesylate inhibits Leydig cell tumor growth: evidence for in vitro and in vivo activity. Cancer Res. 2005;65(5):1897-903.

20. Necchi A, Bratslavsky G, Shapiro O, Elvin JA, Vergilio JA, Killian JK, et al. Genomic Features of Metastatic Testicular Sex Cord Stromal Tumors. Eur Urol Focus. 2019;5(5):748-55.

21. Calaway AC, Tachibana I, Masterson TA, Foster RS, Einhorn LH, Cary C. Oncologic outcomes following surgical Management of Clinical Stage II sex cord stromal tumors. Urology. 2019;127:74-9.

\section{Publisher's Note}

Springer Nature remains neutral with regard to jurisdictional claims in published maps and institutional affiliations.
Ready to submit your research? Choose BMC and benefit from:

- fast, convenient online submission

- thorough peer review by experienced researchers in your field

- rapid publication on acceptance

- support for research data, including large and complex data types

- gold Open Access which fosters wider collaboration and increased citations

- maximum visibility for your research: over $100 \mathrm{M}$ website views per year

At BMC, research is always in progress.

Learn more biomedcentral.com/submissions 